\title{
Effects of dilution procedure and culture conditions after thawing on survival of frozen bovine blastocysts produced in vitro
}

\author{
A. Massip, P. Mermillod, C. Wils and F. Dessy \\ Unité des Sciences Vétérinaires, Université Catholique de Louvain, Place Croix du Sud, 2, B. 1348 \\ Louvain-la-Neuve, Belgium
}

\begin{abstract}
Blastocysts derived from bovine zygotes fertilized and matured in vitro and cultured for 7 days in conditioned medium were frozen in 1.36 mol glycerol $\mathrm{l}^{-1}$ and 0.25 mol sucrose $\mathrm{l}^{-1}$. In vitro survival after thawing was unaffected by dilution rate in $0.25 \mathrm{~mol}$ sucrose $\mathrm{l}^{-1}$. The proportion of blastocysts that re-expanded after $24 \mathrm{~h}$ was $81 \%$ (70 of 86 ) and $47 \%$ (33 of 70 ) hatched. Seven pregnancies beyond 2 months resulted from transfer of 21 blastocysts to 19 recipients. Total embryonic loss was $46.2 \%$, of which $31 \%$ occurred between days 21 and 35 . In vitro survival after thawing was influenced by culture conditions, the best being culture with oviduct epithelial cells, where $55-82 \%$ of blastocysts re-expanded, of which $41-54 \%$ hatched. Conditioned medium also supported re-expansion, but low hatching $(6 \%)$, whereas M199 plus fetal calf serum allowed only limited re-expansion (19-40\%). This behaviour was not a consequence of freezing. It is suggested that blastocysts produced in vitro have reduced metabolic activity leading to high embryonic loss before or just at the time of implantation and that oviduct cells create a favourable environment after thawing, allowing hatching in vitro.
\end{abstract}

\section{Introduction}

Large-scale, low cost production of cattle embryos from ovaries from slaughterhouses by in vitro maturation and fertilization of oocytes would permit extensive commercial exploitation of this technology. Tremendous progress has been made during the last 5-10 years (see reviews by First, 1990; Greve and Madison, 1991; Marquant-Le Guienne, 1991) and some commercial ventures have been established ( $\mathrm{ABC}$ and Ovamass, $\mathrm{UK}$ ) to produce beef embryos of appropriate genetic quality on an industrial scale (Gordon and Lu, 1990; Gordon, 1991). To be used on farms by the classic embryo transfer method, these embryos have to be cultured to the blastocyst stage. This stage is also of interest for research on embryo stem cells from inner cell masses, for example. At present, the yield of transferable embryos produced in vitro varies from 10 to $30 \%$ of the treated oocytes. Their storage in liquid nitrogen would allow greater flexibility in their use. Successful freezing of blastocysts obtained by a totally in vitro technique with subsequent pregnancies or births after transfer have been reported (Lu et al., 1988; Goto et al., 1989; Lu et al., 1990; Reichenbach et al., 1990, 1991; Rorie et al., 1990; Suzuki et al., 1991). In vitro and in vivo survival has also been tested after freezing and thawing of embryos cultured in different conditions (Rorie et al., 1990; Chen Lu et al., 1991) or frozen-thawed by different methods (Lu et al., 1988; Reichenbach et al., 1991). The objective of the present study was to evaluate the effects of dilution procedure and culture conditions after thawing on survival of frozen bovine blastocysts produced by in vitro maturation, fertilization and culture in conditioned medium.

Received 28 December 1991

\section{Materials and Methods}

\section{Source of embryos}

Embryos were generated by in vitro maturation and in vitro fertilization of oocytes from an abattoir according to the method described by Boccart et al. (1991a). Intact cumulusoocyte complexes were matured in tissue culture medium 199 plus $10 \%$ heat-treated fetal calf serum (FCS) supplemented with $0.5 \mu \mathrm{g}$ pure porcine follicle-stimulating hormone (FSH) $\mathrm{ml}^{-1}$, $5 \mu \mathrm{g}$ pure porcine luteinizing hormone $(\mathrm{LH}) \mathrm{ml}^{-1}$ (provided by Beckers, 1987) and $1.0 \mu \mathrm{g}$ oestradiol $\mathrm{ml}^{-1}$ (20 complexes per $100 \mu \mathrm{l}$ droplets). After $24 \mathrm{~h}$ at $39^{\circ} \mathrm{C}$ in a humidified atmosphere under $5 \% \mathrm{CO}_{2}$, cumulus-oocytes with expanded cumulus masses were transferred to fertilization droplets, which consisted of Tyrode's medium supplemented with $6 \mathrm{mg}$ fatty-acid-free bovine serum albumin (Sigma, St Louis, MO) $\mathrm{ml}^{-1}$ and $10 \mu \mathrm{g}$ heparin $\mathrm{ml}^{-1}$ (Calbiochem, San Diego, CA). To each $50 \mu$ l fertilization droplet, $1.0 \times 10^{5}$ percoll-separated spermatozoa were added. Frozen spermatozoa from the same bull were used throughout the experiments. Cumulus-oocyte complexes were removed from fertilization droplets after $18 \mathrm{~h}$, at which time cumulus cells were discarded by gentle pipetting.

\section{Embryo culture before freezing}

Zygotes were placed in culture droplets ( 1 embryo $\mu^{-1}$ ) of conditioned medium (CM) prepared according to Eyestone and First (1989) under mineral oil at $39^{\circ} \mathrm{C}$ in a humidified atmosphere under $5 \% \mathrm{CO}_{2}$. The conditioning period was $48 \mathrm{~h}$ and the medium was stored at $-20^{\circ} \mathrm{C}$ before use. The same batch was 


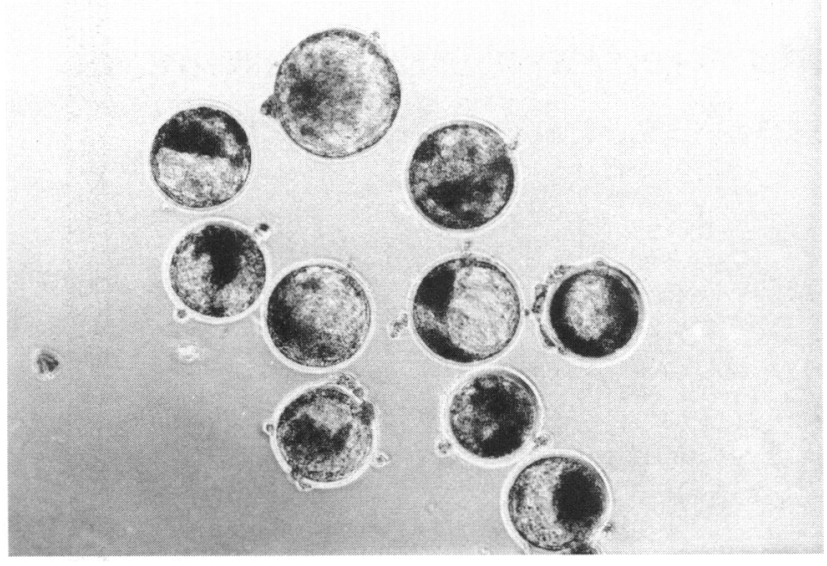

Fig. 1. Bovine blastocysts selected for freezing after culture for 7 days in conditioned medium of oocytes, matured and fertilized in vitro.

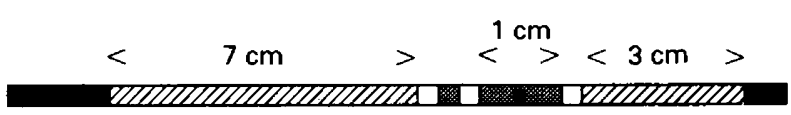

Fig. 2. Diagram of a $0.25 \mathrm{ml}$ straw just before cooling: ( (X) cryoprotectant solution $1.36 \mathrm{~mol}$ glycerol $1^{-1}, 0.25 \mathrm{~mol}$ sucrose $l^{-1}$; (ש) $0.25 \mathrm{~mol}$ sucrose $\mathrm{l}^{-1}$ in phosphate-buffered saline; $(\square)$ air; $(\square)$ plug; $(\mathbf{O})$ bovine embryo.

used during these investigations. Cleavage (5-8 cells) was assessed at $48 \mathrm{~h}$ after insemination. Media were not changed during the course of incubations. Criteria for normal development consisted of attainment of the expanding blastocyst stage after 7 days of culture (Fig. 1). Development results are expressed as a function of oocytes treated. Only embryos derived from one in vitro fertilization that had reached the expanding blastocyst stage with a distinct inner cell mass and blastocoelic cavity were pooled and frozen.

\section{Freeze-thawing and dilution procedures}

At the end of the culture period, expanding blastocysts of normal morphology were washed in phosphate-buffered saline (PBS) supplemented with $20 \%$ FCS and then frozen by the method of Massip and Van der Zwalmen (1984), slightly modified. Briefly, embryos were equilibrated for $10 \mathrm{~min}$ in $1.36 \mathrm{~mol}$ glycerol $\mathrm{l}^{-1}$, and 0.25 mol sucrose $\mathrm{l}^{-1}$ in PBS at room temperature then loaded in $0.25 \mathrm{ml}$ straws (Fig. 2) with a maximum of five embryos per straw.

The proportions of freezing medium and diluent were 1:10. The straws were sealed and placed at $-7^{\circ} \mathrm{C}$ in the cooling chamber of a programmable freezing machine (Minicool: Air Liquide France). After $5 \mathrm{~min}$ at $-7^{\circ} \mathrm{C}$ seeding was induced and, $5 \mathrm{~min}$ later, cooling, at $0.3^{\circ} \mathrm{C} \mathrm{min}{ }^{-1}$ was initiated and interrupted at $-25^{\circ} \mathrm{C}$ before plunging and storing the straws into liquid nitrogen.

Thawing was done by agitating each straw in a $20^{\circ} \mathrm{C}$ water bath for $10-30 \mathrm{~s}$. Two dilution procedures were compared: (a) $1: 10$, the content of each straw was expelled into a Petri dish and mixed by shaking rapidly; after $10 \mathrm{~min}$ at room temperature, embryos were washed twice in PBS for 10 min and cultured; and (b) 1:100, the content of each straw was expelled into a Petri dish

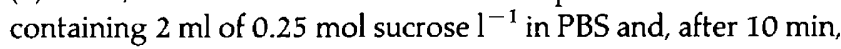
the embryos were treated as in procedure (a).

\section{Embryo culture after thawing}

Experiment 1: effect of dilution procedure. The effect of the dilution procedure was investigated by culturing blastocysts in M199 plus 10\% FCS on bovine oviduct epithelial cell monolayers (BOECM) in four-well dishes (Nunc, Karmstruf, Denmark) containing five to ten embryos under the incubation conditions described previously.

Experiment 2: effect of culture conditions after thawing. To test the effect of culture conditions, dilution by procedure (a) was used, then embryos from the same pool were allocated to two groups: in Expt 2a, group 1 was cocultured in M199 plus 10\% FCS on bovine oviduct epithelial cell monolayers and group 2 was cocultured in M199 plus 10\% FCS alone; in Expt 2b, a third group of embryos cultured in conditioned medium was included. Survival was evaluated as re-expansion after $24 \mathrm{~h}$ (Expt 2a) and $48 \mathrm{~h}$ (Expt 2b) and hatching after 4 days of culture. Some embryos that looked morphologically normal after dilution were transferred nonsurgically to \pm 1 day asynchronous recipients during natural cycles.

\section{Statistical analysis}

Differences between treatments were determined by $\chi^{2}$ analysis.

\section{Results}

\section{Embryo development prior to freezing}

Blastocysts used in our experiments were generated by in vitro maturation and fertilization of 1424 oocytes. Zygotes were then cultured for 7 days in conditioned medium. The cleavage rate (eight cells) after $48 \mathrm{~h}$ was $56 \%$ (804 of 1424) and the yield of blastocysts on day 7 was $19 \%$ (275 of 1424). Some of these blastocysts were then placed in different media on irradiated mouse fibroblast feeder layers in an attempt to produce embryonic stem cells, and the rest were frozen.

\section{Effect of dilution procedure after thawing (Expt 1)}

With the dilution procedure (a) $80 \%$ of frozen-thawed blastocysts re-expanded after $24 \mathrm{~h}$ in culture and $41 \%$ of them hatched after 4 days compared with 83 and $53 \%$ for procedure (b) (Table 1). The differences were not significant.

Twenty-one blastocysts that looked morphologically normal in PBS after thawing were transferred to $19 \pm 1$ day asynchronous recipients $(2 \times 2$ embryos plus $17 \times 1$ embryo $)$. Pregnancy diagnosis was established by determination of plasma progesterone on day 21 , serum pregnancy-associated glycoprotein (PAG) (Zoli et al., 1992) from day 35, both by radioimmunoassay, and by rectal palpation from the second 
Table 1. Effect of dilution after thawing on survival of bovine blastocysts produced in vitro

\begin{tabular}{|c|c|c|c|c|c|}
\hline \multirow[b]{2}{*}{ Dilution } & \multirow{2}{*}{$\begin{array}{c}\text { Embryos } \\
\text { frozen-thawed } \\
(n)\end{array}$} & \multicolumn{2}{|c|}{$\begin{array}{c}\text { Re-expanded } \\
\text { after } 24 \mathrm{~h}\end{array}$} & \multicolumn{2}{|c|}{$\begin{array}{r}\text { Hatched } \\
\text { after } 96 \mathrm{~h}\end{array}$} \\
\hline & & $n$ & $\%$ & $n$ & $\%$ \\
\hline$(a)^{*} 1: 10$ & 40 & 32 & 80 & 13 & 41 \\
\hline (b) $\uparrow 1: 100$ & 46 & 38 & 83 & 20 & 53 \\
\hline Total & 86 & 70 & 81 & 33 & 47 \\
\hline
\end{tabular}

*Dilution of the freezing medium (one part) in ten parts of diluent contained in the straw $(0.25 \mathrm{~mol}$ sucrose I ' in phosphate-buffered saline).

fDilution of the content of the straw in $2 \mathrm{ml}$ of diluent.

Table 2. Effect of culture conditions after thawing on survival of bovine blastocysts produced in vitro (Expt 2a)

\begin{tabular}{|c|c|c|c|c|c|}
\hline \multirow{2}{*}{$\begin{array}{l}\text { Culture } \\
\text { conditions }\end{array}$} & \multirow{2}{*}{$\begin{array}{c}\text { Embryos } \\
\text { frozen-thawed } \\
(n)\end{array}$} & \multicolumn{2}{|c|}{$\begin{array}{c}\text { Re-expanded } \\
\text { after } 24 \mathrm{~h}\end{array}$} & \multicolumn{2}{|c|}{$\begin{array}{l}\text { Hatching } \\
\text { after } 96 \mathrm{l}\end{array}$} \\
\hline & & $n$ & $\%$ & $n$ & $\%$ \\
\hline $\begin{array}{l}\text { Bovine oviduct } \\
\text { epithelial cell } \\
\text { monolayer }\end{array}$ & 61 & 50 & $82^{\mathrm{a}}$ & 27 & $54^{c}$ \\
\hline $\begin{array}{l}199+10 \% \text { fetal calf } \\
\text { serum }\end{array}$ & 55 & 22 & $40^{b}$ & 0 & $0^{d}$ \\
\hline
\end{tabular}

Values within rows with different superscripts are significantly different $P<0.05$.

month. Thirteen recipients $(68 \%)$ had initiated pregnancy on day $2 \mathrm{I}$ (progesterone $>2 \mathrm{ng} \mathrm{ml}^{-1}$ ); $9(47 \%)$ showed PAG + on day 35 ; and $7(37 \%)$ were confirmed by rectal palpation at 2 months. Pregnancy rate at 2 months was $37 \%$ per recipient ( 7 of 19) and $33 \%$ per embryo transferred. Embryonic loss was $31 \%$ (4 of 13) at day 35 and $46 \%$ (6 of 13) at 2 months. If we consider that all animals would have been pregnant at transfer, the total loss is $63 \%$.

\section{Effects of culture conditions after thawing}

Experiment 2a. In vitro development of thawed embryos was significantly higher in coculture than in medium alone $(82 \%$ re-expansion versus $40 \%, \chi^{2}=22, P<0.05$ ). Furthermore, $54 \%$ of re-expanded embryos hatched in coculture and none in the absence of cells $\left(\chi^{2}=32, P<0.05\right.$; Table 2$)$.

Experiment $2 b$. In this experiment, three groups were considered: M199 + 10\% FCS, CM and BOECM. The aim was to determine whether the presence of cells in the culture medium was responsible for the high survival rate after thawing. After $24 \mathrm{~h}$, re-expansion rates in M199 $(19 \%)$ and BOECM $(55 \%)$ were lower than in the previous experiment, but the range was similar (Fig. 3). There was no difference between CM and BOECM. After $48 \mathrm{~h}$, no embryo survived in M199. The re-expansion rate was increased by about $5-10 \%$ (from $55 \%$ to

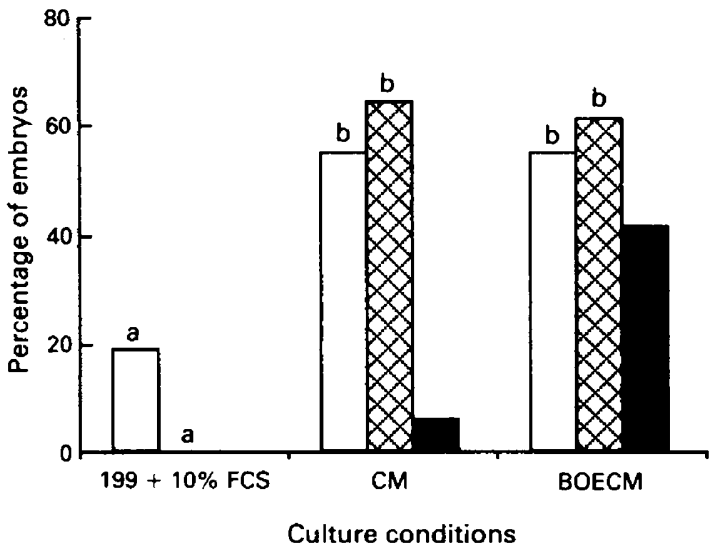

Fig. 3. In vitro survival after thawing of bovine blastocysts placed in different culture conditions for 4 days: TCM199 $+10 \%$ fetal calf serum (FCS; $n=21$ ), conditioned medium (CM; $n=31$ ) and coculture on bovine epithelial cell monolayer (BOECM, $n=31$ ). Survival was examined after $24 \mathrm{~h}(\square)$ and $48 \mathrm{~h}(\nabla)$. Hatching rate $(\square)$ was determined after $96 \mathrm{~h}$. ${ }^{\mathrm{a}, \mathrm{b}, \mathrm{c}}$ Values with different letters differ significantly.

$61-65 \%$ ) both in CM and BOECM. At the end of the culture period, hatching rates were $6 \%$ in $\mathrm{CM}$ and $41 \%$ on BOECM.

\section{Discussion}

With our experimental conditions using conditioned medium, $19 \%$ of treated oocytes reached the blastocyst stage after 7 days of culture. This confirms the results of previous reports (Eyestone and First, 1989; Boccart et al., 1991b; Eyestone et al., 1991; Mermillod et al., 1992) on the efficacy of medium conditioned by oviductal tissue to support embryo development from zygote to blastocyst in vitro. The viability after transfer of such blastocysts has been demonstrated by the birth of calves (Eyestone and First, 1989; Boccart et al., 1991a). In this study, we have shown that they can also be frozen successfully, since, after thawing, $81 \%$ re-expanded after $24 \mathrm{~h}$ of culture and $47 \%$ of them were hatched on day 11 (Table 1). Moreover, seven pregnancies out of 19 transfers are ongoing.

Survival after freezing and thawing was unaffected by the dilution rate in 0.25 mol sucrose $\mathrm{I}^{-1}$ ( 1 of 10 compared with 1 of 100). The original method was developed to allow direct transfer without dilution by mixing sucrose with glycerol in the freezing medium, and a pregnancy rate of $50 \%$ was attained with embryos produced in vivo (Massip et al., 1987). The contribution of sucrose mixed with glycerol is to partially dehydrate the embryo before freezing, by virtue of being a nonpermeating agent. During warming, it prevents osmotic shock. It has also been shown in rabbits (Borland et al., 1976) that, in the presence of sucrose, the blastocyst accumulates $\mathrm{Na}^{+}$and $\mathrm{Cl}^{-}$ions into the blastocoel, the volume of which increases. This transport depends on $\mathrm{Na}^{+}-\mathrm{K}^{+}$ATPase activity. This activity is inhibited by glycerol (Albers and Koval, 1972), so sucrose is involved directly in ion movements through the cells after thawing. The use of 0.25 or $0.5 \mathrm{~mol}$ sucrose $\mathrm{l}^{-1}$ as diluent is not critical for survival, but it may improve the pregnancy rate (Touati et al., 
1990) and, above all, it makes the freezing-thawing procedure safer. However, as sucrose solutions are viscous and may not mix efficiently with cryoprotective agents, it could be better to use galactose solutions of equivalent osmolalities as diluents because monosaccharides have much lower viscosities than disaccharides (McWilliams et al., 1991).

Pregnancy rates after transfer of frozen-thawed bovine blastocysts produced in vitro that were morphologically normal after thawing, are lower than 50\% (Lu et al., 1988; Goto et al., 1989; Reichenbach et al., 1991; Suzuki et al., 1991). This indicates some failure in the development of such embryos. The pregnancy rate in this study was $37 \%$ and embryonic loss was high $(46.2 \%)$ and occurred mainly between days 21 and 35 , just at the time of or before implantation. Heyman (1985) reported embryonic mortality rates of $22.0,28.5$ and $46.4 \%$ after transfer of fresh, frozen and cultured embryos, respectively. In our conditions, in vitro culture and freezing were combined and both affected the viability of the embryo. So, only blastocysts of excellent quality can develop to term. This quality has been stressed as an important factor determining the developmental capacity of blastocysts after transfer or their ability to withstand freezing. It depends on the culture system used (Rorie et al., 1990; Chen Lu et al., 1991; Jiang et al., 1991; Vergos et al., 1991).

Culture conditions have to meet specific requirements at each of the critical steps of embryonic development, i.e. the passage through the block stage, morula compaction, blastocyst formation and hatching, to improve this quality (Ellington et al., 1990).

In vitro survival after thawing was influenced by culture conditions. In Expt 2a, re-expansion rate in M199 was half that in BOECM (40 versus $82 \%$ ) and hatching was zero compared with $54 \%$ (Table 2). The results of Expt $2 \mathrm{~b}$ (Fig. 3) confirm the results of Expt $2 a$ and show that re-expansion rate is poor in M199 plus FCS and similar in CM or BOECM $( \pm 60 \%)$, but hatching rate is very low in CM, $6 \%$ compared with $40 \%$ in BOECM. The same observations were made with nonfrozen blastocysts produced in vitro cultured from day 7 in each of these conditions (Mermillod et al., 1992). This behaviour was therefore independent of the freezing process.

Among the factors that have been shown to affect in vitro development of bovine embryos are medium, protein supplement, gases and the presence or absence of bovine oviduct epithelial cells and their association (Fukui et al., 1991). For example, ova in M199 develop readily in air (20\% oxygen) when cells are present, but development is poor in their absence unless $\mathrm{O}_{2}$ concentration is lowered to $5 \%$. Our incubation conditions were $5 \% \mathrm{CO}_{2}$ in air, and development after thawing was better in M199 plus BOECM than in M199 alone (Table 2). There is, perhaps, an interaction among medium, oviduct, epithelial cells and gases. The cells could mitigate the harmful effects of high oxygen concentrations, probably by reducing the oxygen concentration in the medium or by producing antioxidants, unless they neutralize a toxic effect of serum.

Hatching follows a phase of expansion characterized by high energy requirements, high glutamine and glucose metabolism. Much of the increased metabolic activity in expanded blastocysts is to provide the ATP required by the $\mathrm{Na}^{+}-\mathrm{K}^{+}$pump for expansion of the blastocoel (Tiffin et al., 1991).

This step perhaps needs low oxygen concentration to allow energy substrate utilization. Khurana and Wales (1989) have demonstrated that a reduced oxygen atmosphere is necessary to promote the use of endogenous glycogen pools in cultured mouse morulae. Thus, hatching would depend on the presence of cells.

The specificity for a reproductive-tract source of cocultured cells is not required since a hatching rate of $54 \%$ (47 of 87 ) was found when nonfrozen in vitro blastocysts were cocultured from day 7 in different media on irradiated mouse fibroblast feeder layers (Delhaise et al., 1991). One of these media was M199 plus $10 \%$ FCS plus $10 \%$ calf serum in which $64 \%$ (18 of 20 ) of the blastocysts hatched.

However, fibroblasts differ from oviduct cells because embryos cocultured in their presence have a lower rate of development in vivo than those cultured on oviduct epithelial cells (Gandolfi and Moor, 1987). The viability of embryos thus depends on the presence of oviduct cells that secrete specific proteins (Boice $e t$ al., 1990; Wegner and Killian, 1991), whereas the action of fibroblast cells could be due, in this particular case, to reduction of the oxygen tension or detoxification.

In conclusion, blastocysts derived from bovine zygotes matured and fertilized in vitro and cultured in conditioned medium can be frozen successfully and give pregnancies after transfer. In vitro survival after thawing is unaffected by dilution rate in $0.25 \mathrm{~mol}$ sucrose $1^{-1}$, but is influenced by culture conditions. Re-expansion of blastocysts is limited in M199 plus FCS and, it increases in conditioned medium, but hatching needs an epithelial cell coculture system. This observation is unrelated to freezing and emphasizes the role of coculture on embryo viability.

Research was supported by a grant of the Ministère de l'Agriculture de la Région Wallonne. We thank P. Delahaut for PAG determination, Brabant Province Authorities for facilities for keeping and management of recipient cows provided by $\mathrm{R}$. Van Pee, and E. Van Pee for the opportunity to use his cows as recipients as well as the Sociéte des Abattoirs et Marchés d'Anderlecht.

\section{References}

Albers RW and Koval GJ (1972) Sodium potassium activated adenosinetriphosphate. VII. Concurrent inhibition of $\mathrm{Na}^{+} \mathrm{K}^{+}$adenosine triphosphate and activation of $\mathrm{K}^{+}$nitrophenyl-phosphatase activities Joumal of Biological Chemistry 247 3088-3092

Beckers JF (1987) Isolation and use of a porcine FSH to improve the quality of superovulation in cattle Theriogenology 27213 (Abstract)

Boccart C, Mermillod P, Massip A, Delecoeuillerie C and Dessy F (1991a) Production d'embryons bovins 'in vitro' par coculture avec des cellules d'oviducte après maturation et fécondation 'in vitro' Annales de Médecine Vétérinaire 135 365-371

Boccart C, Mermillod P, Delecoeuillerie C and Dessy F (1991b) Bovine oviduct cell monolayers for supporting the blastocyst formation of bovine embryos Theriogenology 35187 (Abstract)

Boice ML, Geisert RD, Blair RM and Verhage HG (1990) Identification and characterization of bovine oviductal glycoproteins synthetized at estrus Biology of Reproduction 43 457-465

Borland RH, Biggers JD and Lechene CP (1976) Kinetic aspects of rabbit blastocoele fluid accumulation: an application of electron probe microanalysis Developmental Biology 50 201-211

Chen-Lu HB, Huang FL, Lu KH and Polge C (1991) Effect of oviductal cell suspensions on in vitro fertilization and development of bovine oocytes. Report of the 7th European Embryo Transfer Meeting, Cambridge, September 14-15, 134 (Abstract). Fondation Mérieux, Lyon

Delhaise F, Mermillod P, Boccart C, Bralion V and Dessy F (1991) Influence of culture media on the hatching and implantation of in vitro produced bovine 
blastocysts Serono Symposium on Preimplantation Embryo Development, Boston, August 15-18 57 (Abstract). II-13. Serono

Ellington JE, Carney EW, Farrell PB, Simkin ME and Foote RH (1990) Bovine 1-2 cell embryo development using a simple medium in three oviduct epithelial cell co-culture systems Biology of Reproduction 43 97-104

Eyestone WH and First NL (1989) Culture of early bovine embryos with oviductal tissue or in conditioned medium Journal of Reproduction and Fertility 85 715-720

Eyestone WH, Jones JM and First NL (1991) Some factors affecting the efficacy of oviduct tissue-conditioned medium for the culture of early bovine embryos Journal of Reproduction and Fertility 92 59-64

First NL (1990) New animal breeding techniques and their application Journal of Reproduction and Fertility Supplement 41 3-14

Fukui Y, McGowan LT, James RW, Pugh PA and Tervit HR (1991) Factors affecting the in vitro development to blastocysts of bovine oocytes matured and fertilized in vitro Journal of Reproduction and Fertility 92 125-131

Gandolfi F and Moor RM (1987) Stimulation of early embryonic development in sheep by coculture with oviduct epithelial cells Journal of Reproduction and Fertility $8123-28$

Gordon I (1991) Potential application of cattle in vitro fertilization in commercial practice and research Embryo Transfer Newsletter 9 4-9

Gordon I and Lu KH (1990) Production of embryos in vitro and its impact on livestock production Theriogenology 33 77-87

Goto K, Kajihara Y, Kosaka S, Koba M, Nakanishi Y, Ogawa K, Oku T, Fujiyama $M$ and Yoshida $Y$ (1989) Normalities of calves obtained from the transfer of blastocysts produced by totally in vitro technique Australian Joumal of Animal Science 2 591-593

Greve $\mathrm{T}$ and Madison V (1991) In vifro fertilization in cattle: a review Reproduction Nutrition and Development 31 147-157

Heyman Y (1985) Factors affecting the survival of whole and half-embryos transferred in cattle Theriogenology 23 63-75

Jiang HS, Wang WL, Lu KH, Gordon I and Polge C (1991) Roles of different cel] monolayers in the co-culture of IVF bovine embryos Theriogenology 35216 (Abstract)

Khurana NK and Wales RG (1989) Effects of oxygen concentration on the metabolism of $\left(\mathrm{U}-{ }^{14} \mathrm{C}\right)$ glucose by mouse morulae and early blastocysts Reproduction, Fertility and Development 1 99-106

Lu KH, Gordon I, McGovern H and Gallaghan M (1988) Pregnancy established in cattle after transfer of frozen - thawed embryos derived from in vitro fertilization (IVF) of follicular oocytes matured in vitro Proceedings of the 11th Intermational Congress on Animal Reproduction and AI, Dublin, Vol 3 pp 342

Lu KH, Jiang HS, Wang WL and Gordon 1 (1990) Pregnancies established in cattle by transfer of fresh and frozen embryos derived from in vitro maturation and fertilization of oocytes and their subsequent culture in vitro Theriogenology 33278 (Abstract)
McWilliams RB, Gibbons WE and Leibo SP (1991) Osmotic responses of mouse and human ova in permeating and non-permeating solutes Cryobiology 28 523 (Abstract)

Marquant-Le Guienne B (1991) La fécondation in vitro (FIV): l'exemple des bovins Recueil de Médecine Vétérinaire 167 303-312

Massip A and Van der Zwalmen P (1984) Direct transfer of frozen cow embryos in glycerol-sucrose Veterinary Record 115 327-328

Massip A, Van der Zwalmen P and Ectors F (1987) Cryoconservation de l'embryon bovin: techniques et résultats Annales de Médecine Vétérinaire 131 515-528

Mermillod P, Mourmeaux JL, Wils C, Massip A and Dessy F (1992) Protein free oviduct conditioned medium supports complete bovine embryo development Veterinary Record 13013

Reichenbach HD, Liebrich J, Berg U and Brem G (1990) Pregnancy rates and births following transfer of in vitro produced IVM-IVF bovine embryos to synchronous or asynchronous recipients Report of the 6th Scientific Meeting of the European Embryo Transfer Association, Lyon, September 7-8, 182 (Abstract). Fondation Mérieux, Lyon

Reichenbach HD, Liebrich J, Berg U and Brem G (1991) Pregnancy results following transfer of frozen-thawed in vitro produced bovine embryos to recipients Reports of the 7th European Embryo Transfer Meeting, Cambridge, September 14-15, 198 (Abstract). Fondation Mérieux, Lyon

Rorie RW, Xu KP and Betteridge KJ (1990) Effects of culture on the post-thaw viability of cryopreserved in vitro fertilized bovine embryos Theriogenology 33311 (Abstract)

Suzuki T, Yamamoto M, Ooe M, Nishikata Y, Okamoto K and Tsuhihara T (1991) Effect of media on fertilization and development rates of in vitro fertilized embryos, and of age and freezing of embryos on pregnancy rates Theriogenology 35278 (Abstract)

Tiffin GJ, Rieger D, Betteridge KJ, Yadar BR and King WA (1991) Glucose anc glutamine metabolism in pre-attachment cattle embryos in relation to sex anc. stage of development Journal of Reproduction and Fertility 93 125-132

Touati K, Bormans M, Ectors F and Massip A (1990) Congélation d'embryons bovins par la méthode au glycérol-sucrose pour transfert direct après décongélation Annales de Médecine Vétérinaire 134 249-25 I

Vergos E, Kinis A, Lonergan P, Sherif H, Gallagher M and Gordon I (1991) The effect of culture system on the in vitro development of bovine oocyte matured and fertilized in vitro Theriogenology 35290 (Abstract)

Wegner CC and Killian GJ (1991) In vitro and in vivo association of an oviduct estrus associated protein with bovine zona pellucida Molecular Reproduction and Development 29 77-84

Zoli AP, Guilbault LA, Delahaut Ph, Benites-Ortis W and Beckers JF (1992) Radioimmunoassay of a bovine pregnancy associated glycoprotein in serum: its application for pregnancy diagnosis Biology of Reproduction 46 83-93 